\title{
The Inverted Philosopher's Stone: how to turn silver to a base metal
}

\author{
Valentin Radtke ${ }^{1,2}$ (D) Katharina Pütz ${ }^{1,2} \cdot$ Daniel Himmel ${ }^{1,2} \cdot$ Ingo Krossing $^{1,2}$ \\ Received: 28 April 2020 / Revised: 28 April 2020 / Accepted: 4 May 2020 / Published online: 23 May 2020 \\ (C) The Author(s) 2020
}

\begin{abstract}
Metals often are classified as "noble" or "base" - characterizing their reduction potential as one of the most important chemical properties. We show that metals are only as noble as allowed by their environment, i.e. this is a relative term, and the "frame of reference" simply is the solvent in which the redox system is present. We prove that silver is a prime example for a noble metal that forfeits its noble character in the simple ionic liquid HMIM Br (1-hexyl-3-methylimidazolium bromide) as an example for such a solvent.
\end{abstract}

Keywords Hydrogen electrode $\cdot$ Ionic liquid · Ion solvation · Protoelectric Potential Map

\section{Introduction}

A main characteristic of noble metals is their behaviour in acid solutions. A base metal dissolves evolving a gas, whereas a noble metal refuses to do so. Nowadays, the concept of the reduction, or better, electronation potential allows a quantitative description sorting those metals with reduction potentials above zero volts to the noble metals and those below zero volts to the base metals. "Zero volts" means the zero point of the potential scale, which for historic reasons usually belongs to aqueous solution systems and is defined by the redox system $\mathrm{H}^{+}($solv $) / \mathrm{H}_{2}(\mathrm{~g})$. Under standard conditions, i.e. at the temperature $T=298.15 \mathrm{~K}$, the proton activity $a\left(\mathrm{H}^{+}\right.$, solv $)=1$ and the hydrogen pressure $p\left(\mathrm{H}_{2}, \mathrm{~g}\right)=10^{5} \mathrm{~Pa}$, this is called the standard hydrogen electrode SHE. Principally, such scales with a respective $\mathrm{SHE}_{\mathrm{S}}$ can be defined in any solvent $\mathrm{S}$, however, without being readily comparable with each other. These

Dedicated to Prof. Dr. Fritz Scholz on the occasion of his 65th birthday

Electronic supplementary material The online version of this article (https://doi.org/10.1007/s10008-020-04633-y ) contains supplementary material, which is available to authorized users.

Valentin Radtke

valentin.radtke@ac.uni-freiburg.de

1 Institut für Anorganische und Analytische Chemie, Universität Freiburg, Albertstr. 21, 79104 Freiburg, Germany

2 Freiburger Materialforschungszentrum FMF, Universität Freiburg, Stefan-Meier-Str. 21, 79104 Freiburg, Germany zero points are connected to the zero points of the corresponding acidity scales $\mathrm{pH}_{\mathrm{S}}$ in the solvent $\mathrm{S}$ and are, therefore, not comparable as well $[1,2]$. The connection between $\mathrm{SHE}_{\mathrm{S}}$ and $\mathrm{pH}_{\mathrm{S}}$ scales of different solvents $\mathrm{S}_{1}$ and $\mathrm{S}_{2}$ can be achieved with the knowledge of the Gibbs energy of transfer of the proton $\Delta_{\text {tr }} G^{\ominus}\left(\mathrm{H}^{+}, \mathrm{S}_{1} \rightarrow \mathrm{S}_{2}\right)$ from $\mathrm{S}_{1}$ to $\mathrm{S}_{2}$ [3]. Recently, these scales were unified by setting a common zero point of the chemical potential for the electron as well as for the proton, which is the ideal electron gas and ideal proton gas, resp., at standard conditions $[4,5]$. The resulting unified scales of reducity $\mathrm{pe}_{\mathrm{abs}}$ and acidity $\mathrm{pH}_{\mathrm{abs}}$ are defined by the chemical potential of the electron and the proton, resp., and can be combined to the Protoelectric Potential Map (PPM) [6]. Since the relative position of the chemical potentials of chemical entities rules whether a reaction takes place or not, this representation is lucid and instructive. A small pe $\mathrm{abs}_{\mathrm{as}}$ value means a high chemical potential of the electron, i.e. high reducity (high electronation power), and a small $\mathrm{pH}_{\text {abs }}$ value a high chemical potential of the proton, i.e. high acidity (high protonation power). As compendium, a collection of relevant formulae is given in the supporting information.

Gibbs energies of transfer reflect the change in the chemical potential of a particle when the medium changes. The pivotal question is how to get values of $\Delta_{\mathrm{tr}} G^{\ominus}\left(i, \mathrm{~S}_{1} \rightarrow \mathrm{S}_{2}\right)$ of an ion $i$ as an integral part of an arbitrary redox system, and its intricate answer is discussed elsewhere [7, Radtke et al., in review]. Nevertheless, one possibility is the quantum chemical calculation as we executed for $\Delta_{\mathrm{tr}} G^{\ominus}\left(\mathrm{H}^{+}, \mathrm{H}_{2} \mathrm{O} \rightarrow \mathrm{HMIM}\right.$ $\mathrm{Br})$ and $\Delta_{\mathrm{tr}} G^{\ominus}\left(\mathrm{Ag}^{+}, \mathrm{H}_{2} \mathrm{O} \rightarrow \mathrm{HMIM} \mathrm{Br}\right)$; the result of which is represented in the PPM in Fig. 1 (HMIM Br is the ionic liquid 


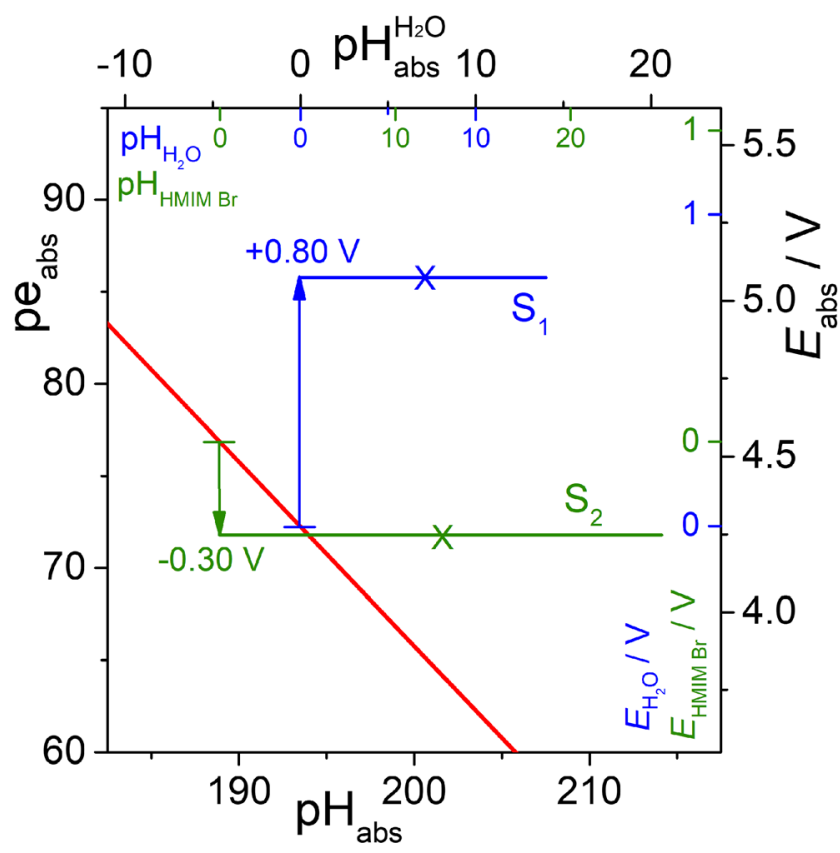

Fig. 1 The redox system $\mathrm{Ag}^{+}($solv, $\mathrm{S}) / \mathrm{Ag}(\mathrm{s})$ in the solvents $\mathrm{S}_{1}=\mathrm{H}_{2} \mathrm{O}$ and $\mathrm{S}_{2}=$ HMIM Br under standard conditions displayed in the PPM. The red line is the hydrogen line representing the redox system $\mathrm{H}^{+}(\operatorname{solv}) / \mathrm{H}_{2}(\mathrm{~g})$. For comparison, the $\mathrm{pH}_{\mathrm{S}}$ and $E_{\mathrm{S}}$ scales are displayed inside of the axes (blue: $\mathrm{H}_{2} \mathrm{O}$; green: HMIM Br). The start of an arrow indicates the potential of the $\mathrm{SHE}_{\mathrm{S}}$ as well as $\mathrm{pH}_{\mathrm{S}}=0$ in $\mathrm{S}$; thus, the arrow tips indicate the standard reducity values $E^{\ominus}{ }_{\mathrm{S}}\left(\mathrm{Ag}^{+} / \mathrm{Ag}, \mathrm{S}\right)$ as given in Fig. 3 and Table 2 . The crosses mark the $\mathrm{pH}$ value for $\mathrm{pH}$ neutrality of $\mathrm{S}$, i.e. $\mathrm{pH}_{\mathrm{S}}$ (neutral) $=0.5 \mathrm{p} K_{\mathrm{AP} \mathrm{s}}$. The values for the aqueous system were taken from the literature [10], and the values for the HMIM Br system were calculated with quantum chemical methods (as described in the SI). The $\mathrm{pH}_{\mathrm{abs}}^{\mathrm{H}_{2} \mathrm{O}}$ value is equivalent to the $\mathrm{pH}_{\mathrm{abs}}$ value being aligned to the zero point of the $\mathrm{pH}_{\mathrm{H}_{2} \mathrm{O}}$ - scale [11] and universally applicable

(IL) 1-hexyl-3-methylimidazolium bromide). Details of the calculations are given in the Supporting Information. Within the PPM, one point represents a distinct state of a redox system. In Fig. 1, the redox system $\mathrm{Ag}^{+}(\mathrm{solv}) / \mathrm{Ag}(\mathrm{s})$ is given in the entire $\mathrm{pH}_{\mathrm{S}}$ range of water $\left(\mathrm{pH}_{\mathrm{H}_{2} \mathrm{O}} 0-14\right.$; blue line) and of HMIM $\mathrm{Br}\left(\mathrm{pH}_{\mathrm{HMIM} \mathrm{Br}} 0-25.2\right.$; green line) at standard conditions ("silver lines"). Also, the redox system $\mathrm{H}^{+}(\mathrm{solv}) / \mathrm{H}_{2}(\mathrm{~g})$ is represented by a red line ("hydrogen line") based on the Gibbs energy of solvation of the proton in water $\Delta_{\text {solv }} G^{\ominus}\left(\mathrm{H}^{+}, \mathrm{H}_{2} \mathrm{O}\right)$ $=-1104.5 \mathrm{~kJ} \mathrm{~mol}^{-1}$ [9]. Within the PPM, Gibbs energies of transfer of $i$ can be readily read off in terms of appropriate cell voltages. At $298.15 \mathrm{~K}$, one pe unit (for any $i$ ) as well as one $\mathrm{pH}$ unit (for $i$ is the proton) counts for $59 \mathrm{mV}$ or $5.71 \mathrm{~kJ} \mathrm{~mol}^{-1}$, provided that the second species of the redox pair is not dissolved (e.g. $\left.\Delta_{\mathrm{tr}} G^{\ominus}\left(\mathrm{Ag}^{+}, \mathrm{H}_{2} \mathrm{O} \rightarrow \mathrm{HMIM} \mathrm{Br}\right) \approx-80 \mathrm{~kJ} \mathrm{~mol}^{-1}\right)$. Otherwise, one can read off the difference of its Gibbs energies of transfer. A reaction only takes place spontaneously if the chemical potential of the reactants are lowered during this reaction. For protons, this means from high to low acidity, for electrons from high to low reducity. Thus, in the PPM representation, protons can only be transferred spontaneously from left to right and electrons only from bottom to top. Under standard conditions (i.e. $\mathrm{pH}_{\mathrm{S}}=0$ ), electrons are spontaneously transferred only from $\mathrm{H}_{2}$ to $\mathrm{Ag}^{+}$in water, and only from $\mathrm{Ag}^{0}$ to $\mathrm{H}^{+}$in HMIM $\mathrm{Br}$.

Figure 1 clearly signals that according to the calculations, silver is a base metal in HMIM Br environment because the left acidic part of the respective silver line lies beneath the hydrogen line. This indicates that silver is de-electronated (oxidized) by protons in acidic HMIM Br solution (neglecting kinetic effects), and this is what matches the character of a base metal.

With this contribution, we devote to the question "Is silver indeed a base metal?" not only by computation but also from experiment.

\section{Experiments, results and discussion}

If yes, silver should dissolve in acidified HMIM Br. To verify this expectation, we gave (under inert conditions) a piece of silver in form of a wire or a flake, resp., to acidic HMIM Br (acidified with anhydrous hydrogen bromide $\mathrm{HBr}$ ) for several weeks and in neutral HMIM Br for more than 6 months, resp. In the acidic IL, the silver flakes dissolved completely and the silver wire exhibited clear signs of etching, see Fig. 2.

We determined the mass change and analyzed the IL solutions by means of atomic absorption spectroscopy (AAS), see Table 1. We observed no effect when using the neutral IL, which also is in accordance with Fig. 1. At the neutral point at $\mathrm{pH}_{\text {abs }} 201.5$ or $\mathrm{pH}_{\mathrm{abs}}^{\mathrm{H}_{2} \mathrm{O}} 8$, the silver line proceeds above the hydrogen line in the PPM, indicating that no de-electronation can take place.

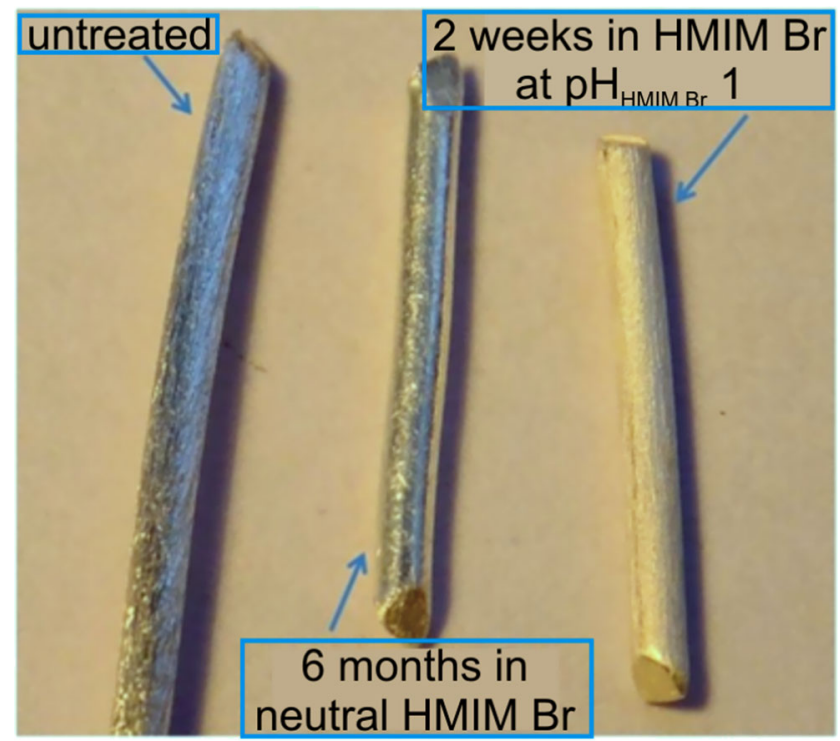

Fig. 2 Three pieces of a silver wire without treatment (left), after treatment in neutral HMIM $\mathrm{Br}$ (middle), and after treatment in acidic HMIM $\mathrm{Br}$ at $\mathrm{pH}_{\text {HMIM } \mathrm{Br}} 1$ (right) 
Table 1 Analytics on the dissolution of silver metal in neutral or acidic HMIM Br

\begin{tabular}{|c|c|c|c|}
\hline Conditions & AAS/ppm & Mass change/mg & Visual inspection \\
\hline $\begin{array}{l}\text { Ag flake; } \\
\mathrm{pH}_{\mathrm{HMIM} \mathrm{Br}}=0 \\
32 \text { days }\end{array}$ & Not executed & -0.51 (whole flake) & Dissolved completely \\
\hline $\begin{array}{l}\text { Ag flake; } \\
\mathrm{pH}_{\text {HMIM Br }}=0.5 \\
19 \text { days }\end{array}$ & 128 & -0.87 (whole flake) & Dissolved completely \\
\hline $\begin{array}{l}\text { Ag wire; } \\
\mathrm{pH}_{\mathrm{HMIM} \mathrm{Br}}=0 \\
32 \text { days }\end{array}$ & Not executed & -15.03 & Etched \\
\hline $\begin{array}{l}\text { Ag wire; } \\
\mathrm{pH}_{\mathrm{HMIM} \mathrm{Br}}=0.5 \\
19 \text { days }\end{array}$ & 747 & -4.76 & Etched \\
\hline $\begin{array}{l}\text { Ag wire; } \\
\mathrm{pH}_{\mathrm{HMIM} \mathrm{Br}}=12.6 \text { (neutral) } \\
>6 \text { months }\end{array}$ & $\begin{array}{l}\text { Not detected } \\
(<0.5)\end{array}$ & 0 & Unchanged \\
\hline
\end{tabular}

This qualitative finding was also analyzed quantitatively by means of potential measurements. For this purpose, "cell I" was assembled and the potential was measured at different $\mathrm{pH}_{\mathrm{HMIM}} \mathrm{Br}$ Values adjusted with anhydrous $\mathrm{HBr}$ as strong acid $\left(c \approx a=10^{-1}-10^{-5} \mathrm{~mol} \mathrm{~L}^{-1}\right.$, i.e. $\left.\mathrm{pH}_{\mathrm{HMIM} \mathrm{Br}}=1-5\right)$ [12] (for details, also on the characterization and setup etc., see the Supporting Information). The $\mathrm{pH}_{\mathrm{HMIM}} \mathrm{Br}$ value used here conforms to our $\mathrm{pH}$ definition in ILs [13], with the assumption that in HMIM Br, the dominating protonated or acidic species is $\mathrm{HBr}_{2}{ }^{-}$instead of $\mathrm{HBr}$ [14] for which we have good experimental validations (see below). Hence, the $\mathrm{pH}_{\mathrm{HMIM}} \mathrm{Br}$ value can readily be converted to the $\mathrm{pH}_{\mathrm{abs}}$ value based on the chemical potential of the proton $[4,5]$.

\section{$\mathrm{Pt}\left|\mathrm{H}_{2}(1 \mathrm{bar})\right| \mathrm{HBr}(\mathrm{c}, \mathrm{HMIM} \mathrm{Br}) ! \vdots \mathrm{AgNTf}_{2}\left(0.01 \mathrm{~mol} \mathrm{~L}^{-1}, \mathrm{HMIM} \mathrm{Br}\right) \mid \mathrm{Ag}$}

The left half-cell is a reversible hydrogen electrode (RHE), the potential of which is $\mathrm{pH}$-dependent by definition. Conversely, a $\mathrm{pH}$-independent redox system (like $\mathrm{Ag}^{+} / \mathrm{Ag}$ ) in connection with a RHE should respond to different potentials at different $\mathrm{pH}$ values with a change of $59 \mathrm{mV}$ per $\mathrm{pH}$ unit. In Fig. 3, experimental as well as computational results are given displaying a quite good agreement, however, with a difference of about $50 \mathrm{mV}$ or $5 \mathrm{~kJ} \mathrm{~mol}^{-1}$. The extrapolationdisregarding the apparently non-ideal value at $\mathrm{pH}_{\mathrm{HMIM}} \mathrm{Br} 1-$ to standard conditions of both half-cells (i.e. $\mathrm{pH}_{\mathrm{HMIM}} \mathrm{Br}=0$ and $\left.a\left(\mathrm{Ag}^{+}, \mathrm{HMIM} \mathrm{Br}\right)=1\right)$ gives $E^{\ominus}{ }_{\text {HMIM Br }}\left(\mathrm{Ag}^{+} / \mathrm{Ag}, \mathrm{HMIM}\right.$ $\mathrm{Br})=-0.35 \mathrm{~V}$ (cf. Table 2$)$. This is in a very good accordance to the calculated value $-0.30 \mathrm{~V}$ (which probably has an error bar around at least $\pm 0.1 \mathrm{~V}$ ). Thus, silver is a non-noble metal in the HMIM Br environment.

To establish the feasibility of the RHE $\mathrm{HMIM} \mathrm{Br}_{\mathrm{Br}}$, the standard rate constant of the heterogeneous electron transfer $k^{0}$ of the hydrogen evolution reaction (HER) was determined by voltammetric measurements at a platinum disc

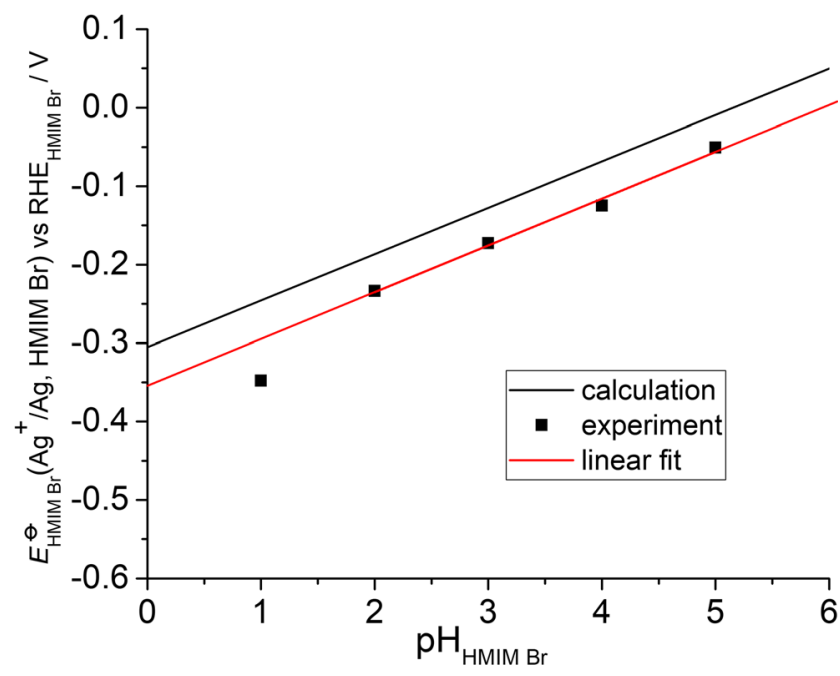

Fig. 3 Calculated (black line) and experimental data of the potential of cell I extrapolated to $a\left(\mathrm{Ag}^{+}, \mathrm{HMIM} \mathrm{Br}\right)=1$ (black squares). The extrapolation to $\mathrm{pH}_{\mathrm{S}}=0$ (red line) gives $E_{\mathrm{S}}^{\ominus}\left(\mathrm{Ag}^{+} / \mathrm{Ag}, \mathrm{S}\right)=-0.35 \mathrm{~V}$; the value at $\mathrm{pH}_{\mathrm{HMIM} \mathrm{Br}} 1$ was not factored, since here the assumption $c \approx a$ is no longer valid 
Table 2 Standard reducity (reduction potential) of $\mathrm{Ag}^{+}$(solv)/Ag. "S" in the parentheses indicates the solvent in which the redox system is present, "S" as subscript indicates the solvent scale; "abs" as subscript indicates the unified scale

\begin{tabular}{llllll}
\hline Solvent S & $\begin{array}{l}\mathrm{pe}_{\text {abs }}^{\ominus} \\
\left(\mathrm{H}^{+} / \mathrm{H}_{2}, \mathrm{~S}\right)\end{array}$ & $\begin{array}{l}\mathrm{pe}_{\text {abs }}^{\ominus} \\
\left(\mathrm{Ag}^{+} / \mathrm{Ag}, \mathrm{S}\right)\end{array}$ & $\begin{array}{l}\Delta \mathrm{pe}_{\text {abs }}^{\ominus} \\
\left(\mathrm{Ag}^{+}-\mathrm{H}^{+}\right)\end{array}$ & $\begin{array}{l}E_{\mathrm{S}}^{\ominus}\left(\mathrm{Ag}^{+} / \mathrm{Ag}, \mathrm{S}\right) \\
/ \mathrm{V}\end{array}$ & $\begin{array}{l}E_{\text {abs }}^{\ominus}\left(\mathrm{Ag}^{+} / \mathrm{Ag} \mathrm{S}\right) \\
/ \mathrm{V}\end{array}$ \\
\hline $\mathrm{H}_{2} \mathrm{O}$ & $72.3^{\mathrm{a}}$ & 85.8 & +13.5 & $+0.80^{\mathrm{b}}$ & +5.07 \\
$\mathrm{HMIM} \mathrm{Br} \mathrm{(calc)}$ & $76.9^{\mathrm{c}}$ & $71.8^{\mathrm{c}}$ & -5.2 & -0.30 & +4.25 \\
HMIM Br (exp) & $76.9^{\mathrm{c}}$ & 70.9 & -6.1 & $-0.35^{\mathrm{d}}$ & +4.19 \\
\hline
\end{tabular}

${ }^{a} \operatorname{Ref}[9]$

${ }^{\mathrm{b}} \operatorname{Ref}[10]$

${ }^{\mathrm{c}}$ This work, calculated with COSMO-RS

${ }^{\mathrm{d}}$ This work, obtained by measurements of cell I ultramicroelectrode (UME) supported by simulations with DigiElch $^{\circledR}$ (Fig. 4). To achieve steady-state voltammograms, we obeyed the relation $v \ll(R T D) /\left(n F r^{2}\right)$ with $v$ as the sweep rate; $r$ as the electrode radius; $D$ as the diffusion coefficient of the electroactive species; and $R, T, n$, and $F$ have their usual meanings [10]. The " $\ll$ " sign was stretched to the factor 500 assuming diffusion coefficients of the electroactive species in the ballpark of $10^{-11} \mathrm{~m}^{2} \mathrm{~s}^{-1}$ due to the rather high viscosity of HMIM Br of 3.99 Pa s [15].

The simulation is a somewhat intricate task, because surface reactions or changes of surface states, resp., cannot be taken into account with DigiElch ${ }^{\circledR}$ in the frame of semiinfinite two-dimensional diffusion simulation, which is mandatory for simulations of UME behaviour. Thus, the simulated $\mathrm{CV}$ shows the normal voltage-current characteristic of a simple one-electron transfer without adsorption or other phenomena (dashed red curve in Fig. 4a). Therefore, forward and reverse sweeps are almost congruent with the given experimental parameters. In the experiment, we observe a nonnormal voltage-current curve. Particularly, the reverse sweep deviates significantly from the forward sweep. On closer inspection, the steady-state current arrives at less negative electrode potential and is lower than in the simulation. These

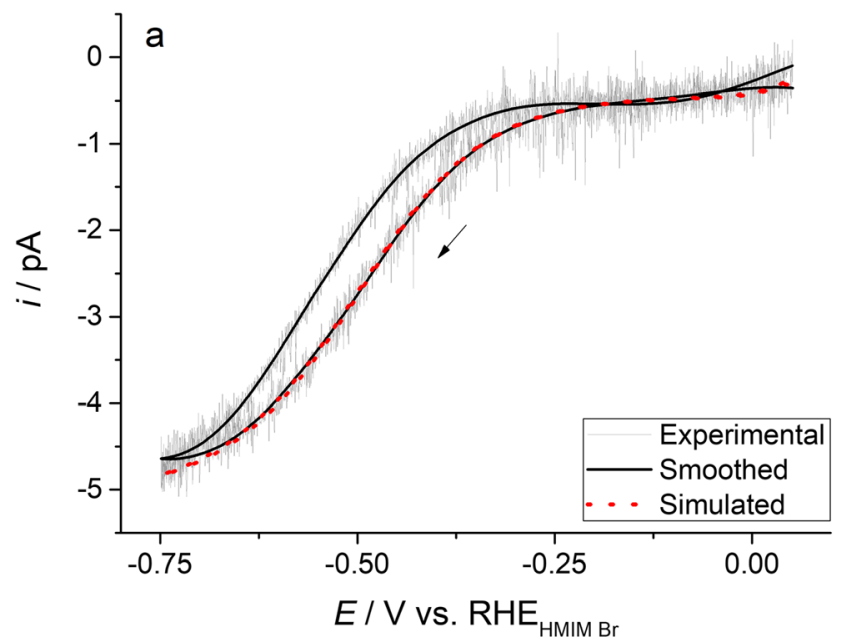

Fig. 4 Cyclic voltammogram (grey curve; smoothed with a SavitzkyGolay filter, black curve) and simulations with DigiElch ${ }^{\circledR}$ aimed at a the forward sweep (dashed red curve) and $\mathbf{b}$ the reverse sweep (dashed observations indicate the deceleration of electrode kinetics reported earlier [16]. Since we intentionally did not activate the electrode-platinum assembled as reference electrode operates without current load at any time-we observe this deceleration during the experiment. Thus, the relevant electrode kinetics has to be determined at early stages of the experiment. In the beginning of the experiment, the deceleration is not recognizable, and the fit of the major share of the forward sweep is straightforward with the following parameters:

$$
\begin{aligned}
D\left(\mathrm{HBr}_{2}{ }^{-}\right) & =1.1210^{-7} \mathrm{~cm}^{2} \mathrm{~s}^{-1} ; \alpha=0.33 \text { and } k^{0} \\
& =2.310^{-7} \mathrm{~cm} \mathrm{~s}^{-1} .
\end{aligned}
$$

A second simulation of this $\mathrm{CV}$ reflecting the experimental reverse sweep was also performed with the same parameters excepting $k^{0}=1.110^{-7} \mathrm{~cm} \mathrm{~s}^{-1}$ (dashed blue curve in Fig. 4b). Thus, during the timeframe of the experiment $\left(810^{4} \mathrm{~s}\right) k^{0}$ more than halved. The diffusion of generated $\mathrm{H}_{2}$ away from the electrode surface, hence $D\left(\mathrm{H}_{2}\right)$, is not relevant for the reductive side of the $\mathrm{CV}$.

This finding essentially is in accordance to other investigations concerning the HER in various ILs other than $\mathrm{Br}^{-}$-ILs [17-19]. The determined rate constant is sufficiently large to

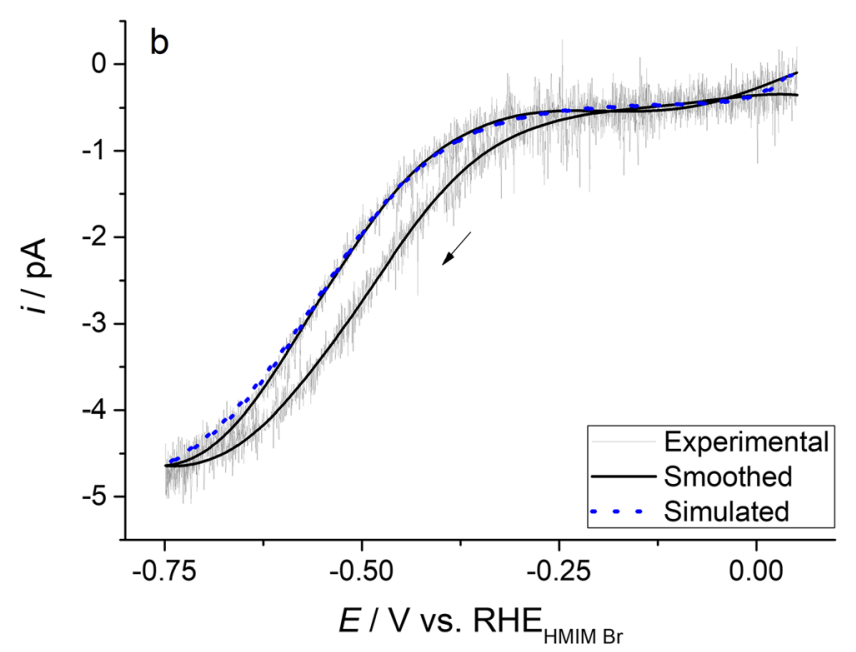

blue curve) of the HER in HMIM Br with $\mathrm{HBr}\left(10^{-4} \mathrm{~mol} \mathrm{~L}^{-1}\right.$, i.e. $\left.\mathrm{pH}_{\text {HMIM Br }}=4\right)$ at a Pt-UME $\left(r_{\text {eff }}=10.6 \mu \mathrm{m}\right), v=0.02 \mathrm{mV} \mathrm{s}^{-1}$; simulation parameters, see text 
use the HER as the reference electrode redox system in HMIM $\mathrm{Br}$, although being about two orders of magnitude lower than that of the HER at platinum electrodes in water $\left(k^{0}=10^{-5} \mathrm{~cm}\right.$ $\left.\mathrm{s}^{-1}[20]\right)$. A rough estimation suggests that electrode reactions with rate constants $k^{0} \gtrsim 10^{-10} \mathrm{~cm} \mathrm{~s}^{-1}$, depending on the used measuring instrument, would be suitable as reference electrodes (for example, the HER at a mercury electrode in water is unsuitable with $k^{0}$ being $10^{-14} \mathrm{~cm} \mathrm{~s}^{-1}$ [20]).

\section{Discussion}

The standard reducity (reduction potential) of silver in the solvent $\mathrm{S}$ is given in Table 2 in terms of different expressions.

The values for $\mathrm{pe}^{\ominus}$ abs $\left(\mathrm{H}^{+} / \mathrm{H}_{2}, \mathrm{HMIM} \mathrm{Br}\right)$ and $\mathrm{pe}^{\ominus}$ abs $\left(\mathrm{Ag}^{+} /\right.$ $\mathrm{Ag}, \mathrm{HMIM} \mathrm{Br}$ ) are not accessible with cell I. Thus, the given $E^{\ominus}$ abs $\left(\mathrm{Ag}^{+} / \mathrm{Ag}, \mathrm{HMIM} \mathrm{Br}\right)$ value is conditionally.

The result of this work clearly shows that the question of whether a metal (or any redox system) is noble or not depends not only on the redox pair itself. Indeed, the role of the medium (i.e. the solvent) and the solvation of the redox active species as well as of the proton are absolutely essential. From Raman spectra [21] (Fig. S2) and NMR experiments (Fig. S3), we deduced that the proton species in HMIM Br is the anion $\left[\mathrm{HBr}_{2}\right]^{-}$as the formal product of the bromidination of an anhydrous $\mathrm{HBr}$ molecule rather than the protonation of a solvent molecule as this is the case in molecular solvents, e.g. for the proton in diethyl ether that gives $\left[\mathrm{H}\left(\mathrm{OEt}_{2}\right)_{2}\right]^{+}[22]$. Analogously, the silver ion dissolves in HMIM $\mathrm{Br}$ as a $\left[\mathrm{AgBr}_{2}\right]^{-}$complex ion. The silver ion is linearly surrounded by two bromide ions as the proton is, and it "feels" relatively to the proton "much more comfortable" with this situation. In other words, the chemical potential upon reaction is lowered so that silver metal now acts as a base metal in this IL and the experimental as well as the computational findings indicate that under standard conditions, the silver ion energetically is more stabilized in HMIM Br than the proton is.

One could argue that the "Inverted Philosopher's Stone" already exists for decades: For example, cyanide leaching for the extraction of noble metals $\mathrm{Nm}$ is based on the decrease of the reduction potential of the redox pair $\mathrm{Nm}^{\mathrm{n}} / \mathrm{Nm}$ due to complexation of $\mathrm{Nm}^{\mathrm{n}+}$ by $\mathrm{CN}^{-}$ions. However, this method means the disallowance of standard conditions or the "natural state" of $\mathrm{Nm}^{\mathrm{n}+}$ in the given solvent. That is, upon addition of cyanide to aqueous silver ion solutions, standard conditions with $a\left(\mathrm{Ag}^{+}\right.$, aq $)=1$ can never be reached due to the very favourable first and second complex formation constants giving $\left[\mathrm{Ag}(\mathrm{CN})_{\mathrm{x}}\right]^{0 /-}(x=1,2)$.

In this context, it is worth to mention the role of silver foil as stabilizer in deuterated chloroform used for NMR experiments. Chloroform $\left(\mathrm{HCCl}_{3}\right)$ easily decomposes in the presence of light with formation of the very strong acid anhydrous $\mathrm{HCl}$. Thus, $\mathrm{HCCl}_{3}$ solutions without stabilizer always are more or less acidic through the evolved $\mathrm{HCl}$. Calculations for the closely related chlorinated solvent 1,2-dichloroethane (DCE) show that the standard redox potential of the $\mathrm{Ag}^{+} / \mathrm{Ag}$ redox system in this solvent is $E^{\ominus}{ }_{\mathrm{DCE}}\left(\mathrm{Ag}^{+} / \mathrm{Ag}, \mathrm{DCE}\right)=-1.06 \mathrm{~V}$; thus, silver is also a base metal in DCE. One may wonder whether solvated protons are present in low polarity solvents as DCE at all. We have recently shown that it is not the existence of solvated protons that primarily determines acidity, but only the protochemical potential [23]. Therefore, high acidities (even superacidity) can be realized in such solvents without even one solvated proton being present. Protonations take place directly from the acid molecule instead of the solvated proton. This is highly probable also for chloroform. Hence, the silver foil is de-electronated by hydrogen chloride as light-induced decomposition product of chloroform, the $\mathrm{Ag}^{+}$-ions form insoluble solid $\mathrm{AgCl}$, and thus the chloroform is stabilized, as given by Eq. 1 .

$$
\mathrm{HCl}_{\mathrm{DCE}}+\mathrm{Ag}^{0}(\mathrm{~s}) \rightarrow 0.5 \mathrm{H}_{2}(\mathrm{~g})+\mathrm{AgCl}(\mathrm{s})
$$

\section{Conclusion}

With a wink we claim to have found the inverse of the Philosopher's Stone, i.e. being able to make noble metals "ignoble". This is possible simply by selecting a suitable solvent in which the relative position of the redox potentials of the systems $\mathrm{H}^{+}($solv $) / \mathrm{H}_{2}(\mathrm{~g})$ and $\mathrm{Nm}^{\mathrm{n}+}(\mathrm{solv}) / \mathrm{Nm}(\mathrm{s})$ is reversed compared with water (Nm is a noble metal). Using silver as a classic example of a noble metal, we demonstrated such an inversion by calculation and experiment with the ionic liquid HMIM $\mathrm{Br}$ as solvent. Principally, it is not excluded that such an inversion also is possible in the other direction, i.e. to make a base metal noble. One has to find a solvent in which the de-electronated metal is less stabilized than the proton compared with water.

Funding information Open Access funding provided by Projekt DEAL. This work was funded through the European Metrology Programme for Innovation and Research (EMPIR) Project 17FUN09 "Realisation of a Unified pH Scale". The EMPIR is jointly funded by the EMPIR participating countries within the European Association of National Metrology Institutes (EURAMET e.V.) and the European Union. We further acknowledge support of the DFG (KR2046/36-1).

Open Access This article is licensed under a Creative Commons Attribution 4.0 International License, which permits use, sharing, adaptation, distribution and reproduction in any medium or format, as long as you give appropriate credit to the original author(s) and the source, provide a link to the Creative Commons licence, and indicate if changes were made. The images or other third party material in this article are included in the article's Creative Commons licence, unless indicated otherwise in a credit line to the material. If material is not included in the article's Creative Commons licence and your intended use is not permitted by statutory regulation or exceeds the permitted use, you will need to obtain permission directly from the copyright holder. To view a copy of this licence, visit http://creativecommons.org/licenses/by/4.0/. 


\section{References}

1. Himmel D, Radtke V, Butschke B, Krossing I (2018) Basic remarks on acidity. Angew Chem Int Ed 57(16):4386-4411

2. Himmel D, Radtke V, Butschke B, Krossing I (2018) Grundlegende Bemerkungen zur Azidität. Angew Chem 130(16): 4471-4498

3. Popovych O, Bates RG (1970) Estimation of medium effects for single ions in non-aqueous solvents. Crit Rev Anal Chem 1(1):73117

4. Himmel D, Goll SK, Leito I et al (2010) A unified pH scale for all phases. Angew Chem Int Ed 49(38):6885-6888

5. Himmel D, Goll SK, Leito I et al (2010) Eine vereinheitlichte pHSkala für alle Phasen. Angew Chem 122(38):7037-7040

6. Radtke V, Himmel D, Pütz K, Goll SK, Krossing I (2014) The Protoelectric Potential Map (PPM): an absolute two-dimensional chemical potential scale for a global understanding of chemistry. Chem Eur J 20(15):4194-4211

7. Radtke V, Ermantraut A, Himmel D, Koslowski T, Leito I, Krossing I (2018) The ideal ionic liquid salt bridge for the direct determination of Gibbs energies of transfer of single ions, part I: the concept. Angew Chem Int Ed 57(9):2344-2347

8. Radtke V, Gebel N, Priester D, et al. submitted

9. Tissandier MD, Cowen KA, Feng WY, Gundlach E, Cohen MH, Earhart AD, Coe JV, Tuttle TR (1998) The proton's absolute aqueous enthalpy and Gibbs free energy of solvation from cluster-ion solvation data. J Phys Chem A 102(40):7787-7794

10. Bard AJ, Faulkner LR (2001) Electrochemical methods: fundamentals and applications, 2nd edn. John Wiley \& Sons, Inc., New York

11. Suu A, Jalukse L, Liigand J, Kruve A, Himmel D, Krossing I, Rosés M, Leito I (2015) Unified pH values of liquid chromatography mobile phases. Anal Chem 87(5):2623-2630

12. Abbott AP, Frisch G, Garrett H, Hartley J (2011) Ionic liquids form ideal solutions. Chem Commun 47(43):11876-11878

13. Himmel D, Goll SK, Scholz F, Radtke V, Leito I, Krossing I (2015) Absolute Brønsted acidities and $\mathrm{pH}$ scales in ionic liquids. ChemPhysChem 16(7):1428-1439
14. Johnson KE, Pagni RM, Bartmess J (2007) Brønsted acids in ionic liquids: fundamentals, organic reactions, and comparisons. Monatsh Chem 138(11):1077-1101

15. Li J-G, Hu Y-F, Sun S-F, Liu YS, Liu ZC (2010) Densities and dynamic viscosities of the binary system (water+1-hexyl-3methylimidazolium bromide) at different temperatures. J Chem Thermodyn 42(7):904-908

16. Silvester DS, Ward KR, Aldous L, Hardacre C, Compton RG (2008) The electrochemical oxidation of hydrogen at activated platinum electrodes in room temperature ionic liquids as solvents. J Electroanal Chem 618(1-2):53-60

17. Meng Y, Aldous L, Belding SR, Compton RG (2012) The hydrogen evolution reaction in a room temperature ionic liquid: mechanism and electrocatalyst trends. Phys Chem Chem Phys 14(15): 5222-5228

18. Meng Y, Aldous L, Belding SR, Compton RG (2012) The formal potentials and electrode kinetics of the proton/hydrogen couple in various room temperature ionic liquids. Chem Commun 48(45): $5572-5574$

19. Bentley CL, Bond AM, Hollenkamp AF, Mahon PJ, Zhang J (2014) Mass transport studies and hydrogen evolution at a platinum electrode using Bis(trifluoromethanesulfonyl)imide as the proton source in ionic liquids and conventional solvents. J Phys Chem C 118(51):29663-29673

20. Hamann CH, Vielstich W (1998) Elektrochemie, 3. Aufl. Wiley$\mathrm{VCH}$, Weinheim

21. Evans JC, Lo GYS (1967) Vibrational spectra of the hydrogen dihalide ions. IV. BrHBr- and BrDBr. J Phys Chem 71(12):39423947

22. Krossing I, Reisinger A (2005) Perfluorinated alkoxyaluminate salts of cationic Brønsted acids: synthesis, structure, and characterization of [H(OEt2)2][Al $\{\mathrm{OC}(\mathrm{CF} 3) 3\} 4]$ and[H(THF)2][Al $\{\mathrm{OC}(\mathrm{CF} 3) 3\} 4]$. Eur J Inorg Chem 2005(10):1979-1989

23. Paenurk E, Kaupmees K, Himmel D, Kütt A, Kaljurand I, Koppel IA, Krossing I, Leito I (2017) A unified view to Bronsted acidity scales: do we need solvated protons? Chem Sci 8(10):6964-6973

Publisher's note Springer Nature remains neutral with regard to jurisdictional claims in published maps and institutional affiliations. 